\title{
The Effect of Adipose Tissue-Derived Mesenchymal Stem Cells on Regeneration of Uterine Scars
}

\author{
R. Ada BENDER ${ }^{1}$, Aykan YÜCEL², Volkan NOYAN'1, Aylin GÜRPINAR ${ }^{3}$, Pinar ATASOY 4 , Faruk M. COMU \\ Kirlkkale, Turkey
}

\begin{abstract}
OBJECTIVE: The mesenchymal stem cell application to uterine healing scars may provide better tissue strength.

STUDY DESIGN: Hysterectomy was performed on rats, and the wound recovery as a result of primary suturing was evaluated as tissue stretching and the positive histopathological effects. The mesenchymal stem cells originating from the adipose tissue were used during the healing period of the wound and would differentiate to mesenchyme-originated cells present in intact tissue for an optimum level of healing.

RESULTS: The weights of non-incised uterine horns in the control group were found to be significantly higher than the weights of the incised uterine horns $(z=2.52, p=0.012)$. In the experiment group, the weights of the incised uterine horns were found to be significantly higher than the non-incised uterine horns $(z=2.52, p=0.012)$. In the control group, the non-incised uterine horns withstood the stretching test to a higher extent than the incised horns, and a significant difference was found between the stretching values $(z=2.5, p=0.012)$. In the experiment group, the incised uterine horns withstood the stretching tests to a higher extent than the non-incised uterine horns; however, there was no significant difference between the stretching tests $(z=1.540, p=0.123)$.
\end{abstract}

CONCLUSION: Adipose tissue-originated mesenchyme stem cells were observed to increase the tissue stretching during wound healing.

Keywords: Mesenchymal stem cells, Tissue stretching, Angiogenesis, Wound healing, Uterine scar

Gynecol Obstet Reprod Med 2017;23(3):120-128

\section{Introduction}

Stem cells are non-differentiated cells and yet have the ability to regenerate. While they can differentiate into tissues they

${ }^{I}$ Kirlkkale University School of Medicine Department of Obstetrics and Gynecology, and ${ }^{4}$ Department of Pathology, and ${ }^{5}$ Department of Physiology, Kırlkkale

2 Zekai Tahir Burak Women's Health Care Training and Research Hospital, Ankara

${ }^{3}$ Hacettepe University Department of Biology, Ankara

Address of Correspondence: Aykan Yücel

Zekai Tahir Burak Women's Health Care Training and Research Hospital Ankara, Turkey aykanyucel@gmail.com

Submitted for Publication: $\quad 20.12 .2016$ Accepted for Publication: $\quad$ 04.01.2017

: The manuscript has been presented as an oral communication at the XXIV. European Congress of Perinatal Medicine, Jun 6 ${ }^{\text {th }}$, 2014, Florence, Italy. The study was financially supported by Kirlkkale University Scientific Research Projects Coordination Unit, Kirlkkale, Turkey, with grant number 2012/75.

\begin{tabular}{|c|c|}
\hline & Access this article online \\
\hline $\begin{array}{c}\text { Quick Response Code: } \\
\text { D. }\end{array}$ & Website: www.gorm.com.tr \\
\cline { 2 - 2 } & DOI:10.201613/GORM.2016.654 \\
\hline
\end{tabular}

How to cite this article: Bender RA. Yücel A. Noyan V. Gürpinar A. Atasoy P. Comu FM. The Effect of Adipose Tissue-Derived Mesenchymal Stem Cells on Regeneration of Uterine Scars. Gynecol Obstet Reprod Med 2017;23(3):120128 originate from, they can also differentiate into other tissues by means of the environment and biological stimulants (1).

Having non-immunologic property in general and with the various factors they release, mesenchyme stem cells (MSC) contribute to the healing of the damaged tissue at the application site when they are transplanted with their immigration abilities and capability of fusion at the tissue with the damaged cell (2). MSC are multi-potent cells with the ability of differentiation to bone, cartilage, lipid, and ligament and tendon cells other than the hematopoietic group (3). There is no complete consensus yet on characterization of MSC; however, some basic criteria have been created. There are three accepted criteria at this point: (4) MSC should be able to adhere onto plastic culture surfaces, CD105, CD73 and CD90 (+); however, CD45, CD34, CD14, CD11b, CD79a, CD19 and HLA-DR should be (-), and they should be able to differentiate to osteoblast, chondroblast and adipocytes in in vitro conditions.

With their adipogenic, osteogenic, chondrogenic, neurogenic and myogenic differentiation abilities in in vitro conditions and their easy obtainability in large amounts, human adipose tissue stem cells and their use for treatment purposes in pre-clinical studies are promising (5). Furthermore, the probability of producing an immune response of adipose tissue stem cells is lower and more stable genetically when compared to bone marrow stem cells at culture conditions in the long term (6). The clinically safe and more common use of 
adipose tissue stem cells are due to the good characterization of these cells in vitro (7).

The aim of the present study was to determine the wound healing and evaluate tissue stretching consequent to primary saturation, and to evaluate histopathologically.

\section{Material and Method}

This experimental study was approved by the Ethics Committee of Experimental Animals, Kırıkkale University with the date of 26.04.2012 and the 12/04 meeting and 12/171 decision number, performed in accordance with the ethical rules.

Nineteen Wistar Albino type female rats weighing 250-300 gr, of the same age were used in the study. ATOSC (adipose tissue-originated stem cells) was prepared from randomly chosen 3 rats that would be used in the experiment. They were kept in stainless steel cages, in quiet, at $17 \pm 2{ }^{\circ} \mathrm{C}$ temperature, and the humidity was maintained between $60 \%-65 \%$, Furthermore, the room was maintained at a cycle of 12 hours of light and 12 hours of darkness. They were fed with the standard pellet feed and drinking water. Appropriate aseptic conditions and anesthesia were provided for each of them during the surgical procedures.

The ATOSC used in this study was prepared using the simple technique at the Hacettepe University Faculty of Science, Department of Biology (8). The rats were anesthetized with Xylazine (Richter Pharma AG, Austria) $(10 \mathrm{mg} / \mathrm{kg}$ ) and ketamine (Richter Pharmacy AG) (50 mg/kg), and the adipose tissue was collected from the flank area under sterile conditions. The isolation procedure was repeated 3 times and a mean 0.62 gr of adipose tissue was collected from each rat $\left(\mathrm{n}=3 ; \mathrm{n}_{1}=\right.$ $0.72 \mathrm{gr}, \mathrm{n}_{2}=0.57 \mathrm{gr}, \mathrm{n}_{3}=0.57 \mathrm{gr}$ ). For the transportation of the adipose tissue, the DMEM/F12 (Biochrom, Germany) medium, including 10\% (v/v) FBS (Biochrom, Germany) and $0.4 \%$ (v/v) penicillin-streptomycin (Sigma Chemicals, USA) was used and then placed in petri dishes and they were fractioned to pieces of 4-5 mm of thickness. The content of the tissue pieces was incubated in the main medium (DMEM/F12) including $20 \%(\mathrm{v} / \mathrm{v}) \mathrm{FBS}$ and $0.4 \%(\mathrm{v} / \mathrm{v})$ penicillin - streptomycin inside 6 nested culture dishes under standard conditions (humidified 95\% air and 5\% CO including atmosphere at 37 ${ }^{\circ} \mathrm{C}$ ). With renewal of culture mediums every day, the probable various effects of the cytokines on MSC's were prevented. Using the standard trypsinization method for the passage of cells, the number of cells marked with trypan blue (Sigma Chemical) was calculated. Trypan blue detects dead cells. Live and proliferative cells do not absorb trypan blue because of their intact membranes and they are not stained. The culture medium was removed and the added cells were obtained with trypsin/EDTA (\%0.05/0.02) solution (Biochrom). The cell suspension was placed in centrifuge tubes and centrifuged at $800 \mathrm{rpm}$ for 5 minutes. The supernatant was extracted care- fully and the cells were incubated inside DMEM/F12 including $10 \%(\mathrm{v} / \mathrm{v})$ FBS and $0.2 \%(\mathrm{v} / \mathrm{v})$ penicillin-streptomycin. The MSCs were passaged 4 times and they were frozen for future use. By extracting the cells from the surface of the culture dish with Trypsin /EDTA solution, they were prepared for freezing. The cell suspension was quickly transferred to a cooling medium including 50\% (v/v) FBS, 40\% DMEM/F12 and $10 \%(\mathrm{v} / \mathrm{v})$ DMSO (Sigma Chemical), inside a cryogenic tube. The cryo tubes were stored at $-80^{\circ} \mathrm{C}$ for 48 hours and the frozen tubes were then transferred to $-196{ }^{\circ} \mathrm{C}$ liquid nitrogen including containers for long term storage. For future use, in order to standardize cell concentration, all the cells were collected from 6 nested culture dishes and transferred to 1 cryogenic tube. The cell morphology and growth were evaluated on an inverted microscope (1x70, Olympus, Japan).

\section{Cell Characterization}

The marking method with CD13 and CD29 molecules (Santa Cruz Biotechnology, USA) was used for MSC characterization. For immune marking, the mature cells were washed in culture dishes with PBS (Biochrom) and fixed inside methanol at $-10{ }^{\circ} \mathrm{C}$ for 5 minutes. Following fixation, methanol was removed and dried. For blocking, the cells were kept inside blocking serum (normal goat serum) for 20 minutes. Following blockade, the blocking serum was removed and the cells were washed in PBS for 3 times and then they were incubated with the antibodies of primary CD13 and CD29 molecules for 1 hour. Following 5 minutes of washing with PBS, the cells were washed for 45 minutes with secondary antibodies (donkey anti-goat Ig-TR) and 3 times with PBS. After washing, the cells were placed on the surface they are going to be examined on, and examined using the fluorescent microscope (BH2-RFL-T3 model fluorescence device, Olympus). Flow cytometer study for MSC characterization was performed against CD29, CD90, CD54, MHC Class 1, CD45, CD106 and MHC Class 2 (9).

\section{Cell Isolation and Culture Results}

The primary explant culture technique was used for cell isolation. The non-enzymatic digestion method was preferred. Tissue fragments belonging to adipose tissue were directly placed into 6 nested culture dishes. After the $18^{\text {th }}$ hour of culture, the cells in fibroblastic morphology were emerged and the erythrocytes among them were identified.

The number of cells in fibroblastic morphology was increased after 7 days and the intersection at the different pieces of the culture plate was examined. Many erythrocytes were removed by changing the culture medium and all the red blood cells had completely disappeared before the first passage. Although cells did not intersect completely, they were passaged on the $7^{\text {th }}$ day of primary culture. The number of cells was approximately a mean of 600.000 cells $/ \mathrm{mL}\left(\mathrm{n}=3 ; \mathrm{n}_{1}=\right.$ 400,000 cells $/ \mathrm{mL}, \mathrm{n}_{2}=640.000$ cells $/ \mathrm{mL}, \mathrm{n}_{3}=750.000$ cells $/ \mathrm{ml}$ ) at the beginning of the first passage in 6 nested culture dishes. 
The number of cells was rapidly increased compared to the primary cells after the first passage. On the $4^{\text {th }}$ day of the first passage, the number of cells reached a mean of 900.000 cells $/ \mathrm{mL}\left(\mathrm{n}=3 ; \mathrm{n}_{1}=1,320.000\right.$ cells $/ \mathrm{mL}, \mathrm{n}_{2}=760.000$ cells $/ \mathrm{mL}$, $\mathrm{n}_{3}=600.000$ cells $\left./ \mathrm{mL}\right)$.

If the cells were intersected, they were passaged twice a week. As the culture continued, half of the cells were frozen in each passage and kept for further use. The cell reproducing procedure was continued for 3 weeks. At the end of this period, 300.000.000 cells were obtained in total from each rat (900.000.000 cells from 3 rats).

After the fibroblastic cell morphology freezing and storage procedure, the procedure was continued for the stimulated and the non-stimulated subculture conditions.

In this study, CD13 and CD29 expressions were used for MSC identification. According to the results of immune fluorescent methods, the characterizations of the cultured cells were performed by demonstrating that they are CD13 and CD29 positive.

The remaining 16 rats were randomly divided into experiment and control groups so that there would be 8 rats in each group. In the control group: incision was performed onto the left uterine horn and only primarily sutured. In the experiment group: incision was performed onto the left uterine horn, and ATMSC was placed onto the incision line after primary suturing. Of the two horns of the uterus, a $1.5-2 \mathrm{~cm}$ vertical incision that would reach the endometrial cavity was performed on the left horn. The incision area was then separately sutured with 4.0 rapid vicryl. $1 \mathrm{cmx} 1 \mathrm{~cm}$ sponge-absorbed MSCs were placed on the incision lines of the uterus in the experiment group. The abdominal incisions in both groups were closed with 4.0 rapid vicryl. One month after the initial process, laparotomy was performed on the rats through the same anesthesia and same incision, and both horns were surgically removed for the tissue stretching test and histopathological evaluation. The rats were then sacrificed with high dose anesthesia. In both groups, the uterine horns were weighed with precision scales, and at least 1 hour after the hysterectomy, stretching was applied in order to save the tissue elasticity and strength. The residual tissues after tissue stretching were kept in $10 \%$ phosphate-tamponed formaldehyde solution for histopathological analyses.

Separate stretching was applied to the uterine horns in both groups. Tissue Stretching System (Commat LTD, Turkey) and integrated Tissue Stretching Recording System (MP30) were used for the tissue-stretching test. Tissue stretching recordings were made at the Kırıkkale University School of Medicine Physiology Department, at normal room temperature $\left(20 \pm 2^{\circ} \mathrm{C}\right)$, in an isolated room for external factors. The recordings were analyzed with the MP30 system.
The tissue samples were placed at the ends of the transducer parallel to the uterine incision performed (Figure 1). Force was applied in this direction so that it would be equal at both ends. In the simultaneously made records, the yield point of the tissue was determined and the maximum withstanding stretching of the tissue was calculated in $\mathrm{kg}$.

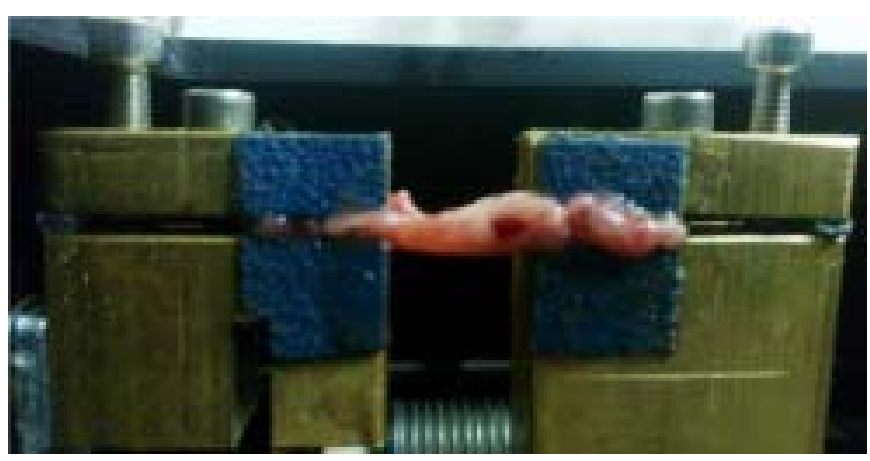

Figure 1: The tissue samples were placed at the ends of the transducer parallel to the uterine incision performed

The preparations that were prepared with hematoxylineosin for histopathology evaluation were examined with the microscope (Carl Zeiss - Germany) at x40, x100 and x 400 magnification. While the uterine horn cross-sections were evaluated histopathologically, semi-quantitative scoring in five categories was performed as detachment, bleeding, edema, mononuclear leucocyte infiltration and angiogenesis.

In the direction of the obtained data, each group was divided in pairs so as to include intact and incised uteri, and the statistical analyses were performed with these two variables in these groups as: first between the weight, and then stretching, and finally for histological examination for bleeding, edema, mononuclear leucocyte infiltration and angiogenesis variables separately. The IBM SPSS Statistics 20.00 and Power-G 3.00 package program was used for the data analysis. Before the data analysis, due to the fact that the number of subjects would be lower, the comparative power analysis was performed and the number of subjects and the statistical power were calculated. The distribution of the continuous variables according to the groups was demonstrated by the graph. The Wilcoxon Signed Ranking test, which is a non-parametric test, was used for evaluation of the intergroup differences between the intact and the incised weight and stretching values, since the number of subjects was very low in the groups. Furthermore, the Mann Whitney U test was used to evaluate whether or not there was a difference between the experiment and the control groups for weight and stretching values. While evaluating the pathology results in terms of being intact and incised, whether or not there was a difference between the detachment, bleeding, edema, mononuclear leucocyte infiltration and angiogenesis of the experiment and the control groups, this was evaluated with the chi-square independence test, since these variables were in the classification level. The difference between the intact and incised subjects in the experiment and the control 
groups were tested with the Friedman test, which is one of the non-parametric tests. In the results, a $p$ value of $<0.05$ was accepted to be statistically significant.

\section{Results}

Compromised power analysis was performed. The "Power-G 3.00" program was used for the analysis. As a result of the analysis, it was determined that at the $\beta / \alpha=0.05$ level and impact size of 0.20 and when a total of 16 subjects was used in the control and the experiment groups, it would yield a $70 \%$ power for the number of subjects in the study.

In both groups, to evaluate the difference of weight between the non-incised and the incised uterine horns were significant, the related samples were tested with the Wilcoxon Signed Ranking test. As a result of analysis, the weights of non-incised uterine horns in the control group were found to be significantly higher than the weights of the incised uterine horns $(\mathrm{z}=2.52, \mathrm{p}=0.012)$. In the experiment group, the weights of the incised uterine horns were found to be significantly higher than the non-incised uterine horns $(\mathrm{z}=2.527, \mathrm{p}=0.012)$ (Figure 2).

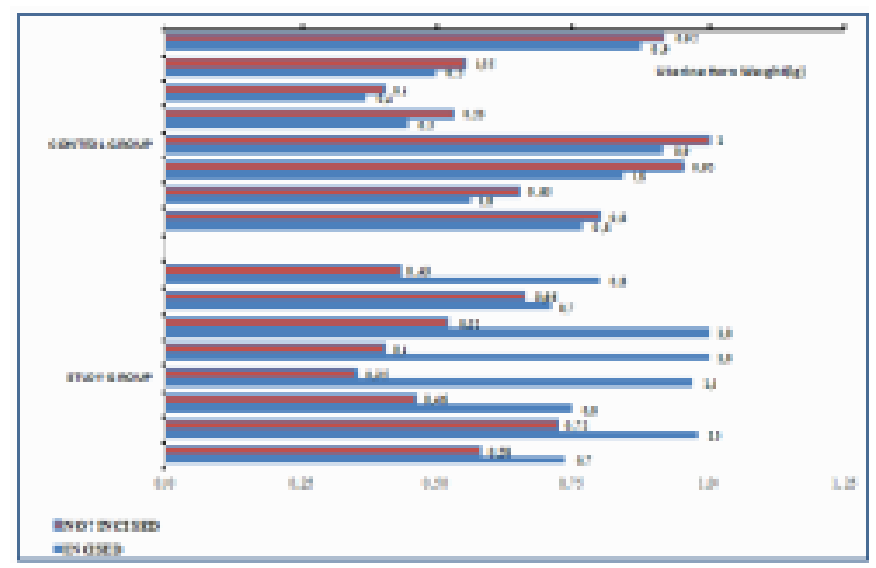

Figure 2: Comparison of the weights of incised and non-incised horns in study and control group.

- In control group, the weights of the incised horns were significantly lower comparing to the non-incised horns $(p=0.012)$.

- In the study group, weights were significantly higher comparing to non-incised horns $(p=0.012)$.

In both groups, the Wilcoxon Signed Ranking test, which is a non-parametric test, was used to evaluate whether or not the difference of stretching values between the non-incised and incised uterine horns were significant. It was observed that in the control group, the non-incised uterine horns withstood the stretching test to a higher extent than the incised horns, and a significant difference was found between the stretching values $(\mathrm{z}=2.51, \mathrm{p}=0.012)$. At the same time, it was observed that in the experiment group, the incised uterine horns withstood the stretching tests to a higher extent than the non-incised uterine horns; however, there was no significant difference between the stretching tests $(\mathrm{z}=1.540, \mathrm{p}=0.123)$ (Figure 3).

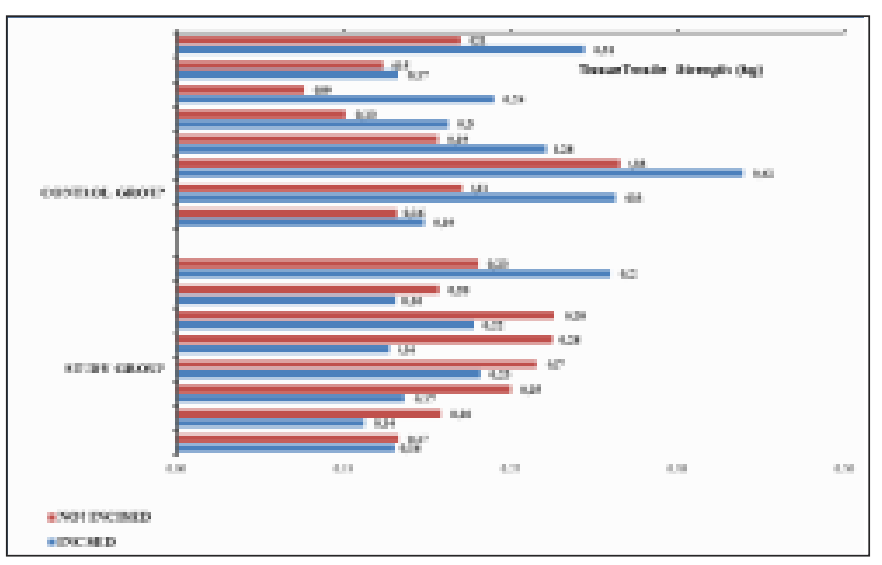

Figure 3: Comparison of the tissue tensile strength of incised and non-incised horns in study and control group.

In the control group, the incised horns had significantly reduced tensile strength in comparison with non-incised horns $(p=0.012)$; but in the study group, no difference was observed between the incised and nonincised horns $(p=0.123)$.

The Mann Whitney $U$ test was used to examine whether there was a difference between the experiment and the control group in terms of weight and stretching values. There was no significant difference between the experiment and the control groups in terms of the weight values of the non-incised uterine horns $(U=14,5 \mathrm{p}>0.05)$. Similarly, it was observed that there was no significant difference in terms of the weight values of the incised uterine horns $(U=15, p>0.05)$ (Table 1).

Table 1: Comparison of the tissue tensile strength and weight of incised and non-incised horns in study and control group.

\begin{tabular}{llrl}
\hline & Group & $\mathrm{n}$ & $\mathrm{p}$ \\
\hline Non-incised weight & Study & 8 & 0.06 \\
& Control & 8 & \\
& Total & 16 & \\
\hline Incised weight & Study & 8 & 0.07 \\
& Control & 8 & \\
& Total & 16 & \\
\hline Non-incised tensile strength & Study & 8 & 0.07 \\
& Control & 8 & \\
& Total & 16 & \\
\hline Incised tensile strength & Study & 8 & $0.04^{*}$ \\
& Control & 8 & \\
& Total & 16 & \\
\hline
\end{tabular}

${ }^{*} p<0,05$

- Non-incised horns of the study and control group were comparable in terms of weight and tissue tensile strength $(p=0.06, p=0.07$, respectively).

- No significant difference existed among the weights of the incised horns of study and control group ( $p=0.07$ ).

- The incised horns in the study group had higher values in terms of tensile strength $(p=0.04)$

Another finding obtained as a result of the analysis was that there was no difference between the experiment and the control group in terms of the stretching values of the non-incised uterine horns $(U=15.0, p>0.05)$; however, the resistance 
of incised uterine horns to stretching was higher in the control group than the experiment group, and the difference was significant $(\mathrm{U}=13.0 \mathrm{p}<0.05)$ (Table 1$)$.

While the pathology results were being examined, the chisquare independence test was used to examine whether or not there was a difference between detachment, bleeding, edema, mononuclear cell infiltration and angiogenesis values of the experiment and the control groups. As a result of the analysis, no significant difference was determined in the experiment and the control groups with non-incised uterine horns for detachment, bleeding, edema, mononuclear cell infiltration and angiogenesis values $(p<0.05)$. There was an increase in the control group for frequency of "edema" $\left(\chi^{2}(2)=6,571 ; p<0,05\right)$ (Figure $4 \mathrm{a}$ ) and "mononuclear cell infiltration" $\left(\chi^{2}(1)=6,349\right.$;

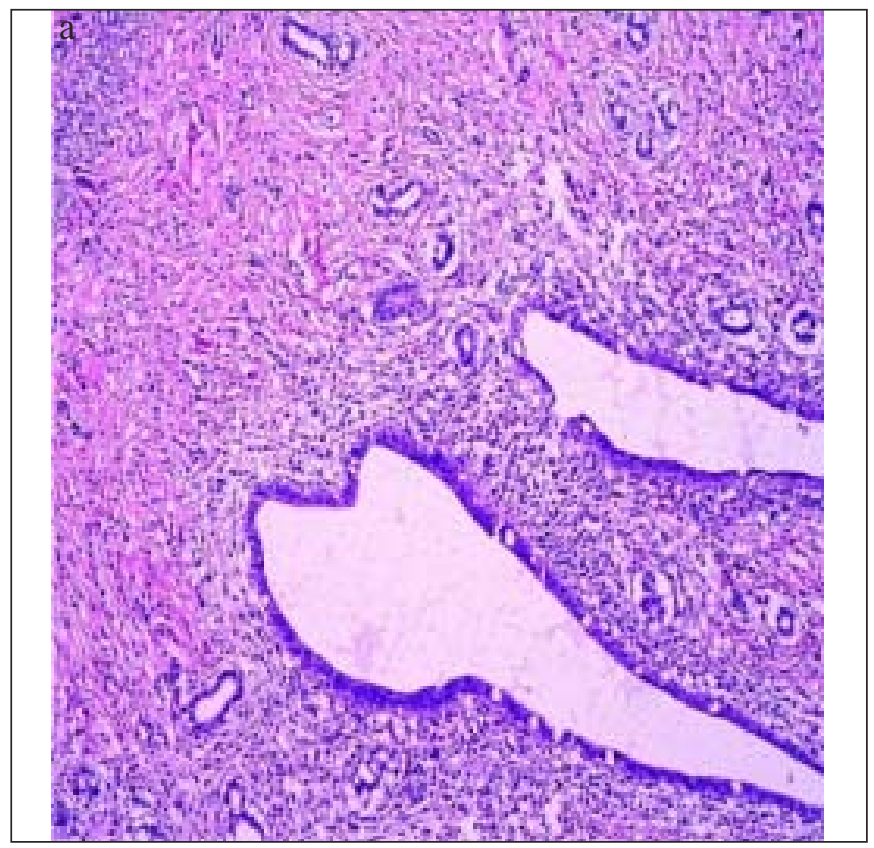

$p<0,05$ ) (Figure $4 b$ ), and the difference was found to be significant. No significant difference was observed for the other states $(\mathrm{p}>0,05)$. In the experiment and the control groups, the Friedman test, which is one of the non-parametric tests, was used to evaluate whether there was a difference between the pathology data of the non-incised and the incised uterus horns. As a result of the analysis, in the experiment group, bleeding $\left(\chi^{2}(1)=4.00 ; \mathrm{p}<0.05\right) \quad\left(\right.$ Figure 5a), detachment $\left(\chi^{2}(2)=4,00\right.$; $\mathrm{p}<0,05)$ (Figure 5b) and angiogenesis $\left(\chi^{2}(1)=4,00 ; \mathrm{p}<0.05\right)$ (Figure $5 \mathrm{c}$ ) in the incised uterine horns were found to be significantly higher than the non-incised uterine horns. In the incised uterine horns in the control group, there was a significant difference that was determined only for the incidence of mononuclear cell infiltration than the non-incised uterine horns $\left(\chi^{2}(1)=5,00 ; \mathrm{p}<0.05\right)$.

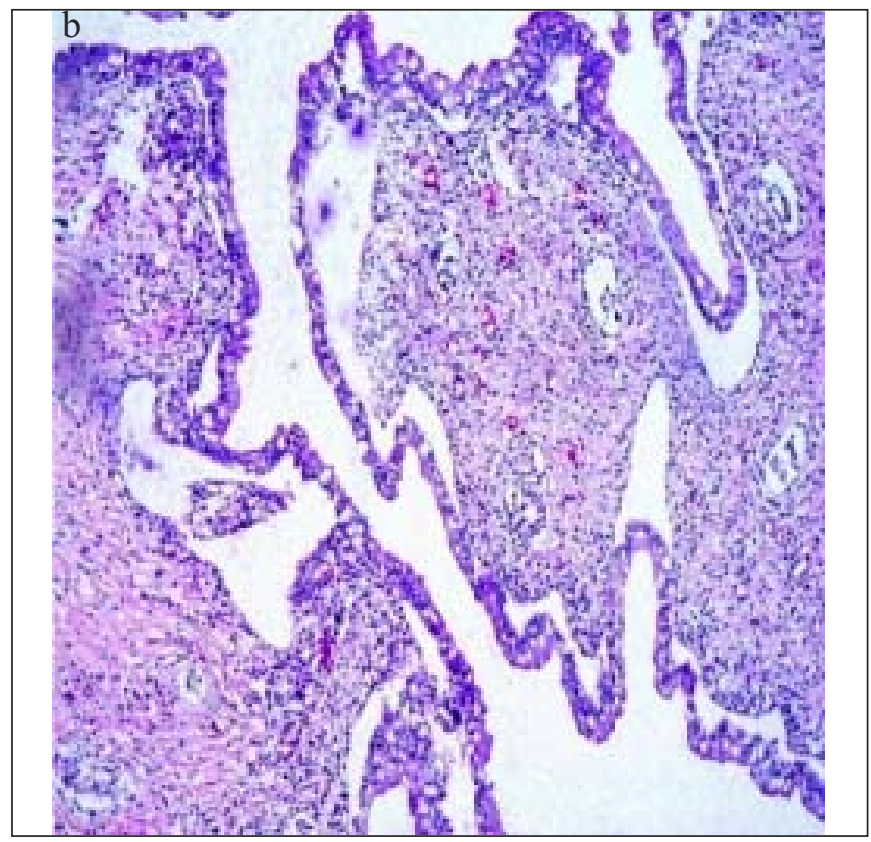

Figure 4: The incised horns of control group had significantly higher amount of edema (a) and mononuclear cell infiltration (b) and there was no other significant difference (H\&E, x100)

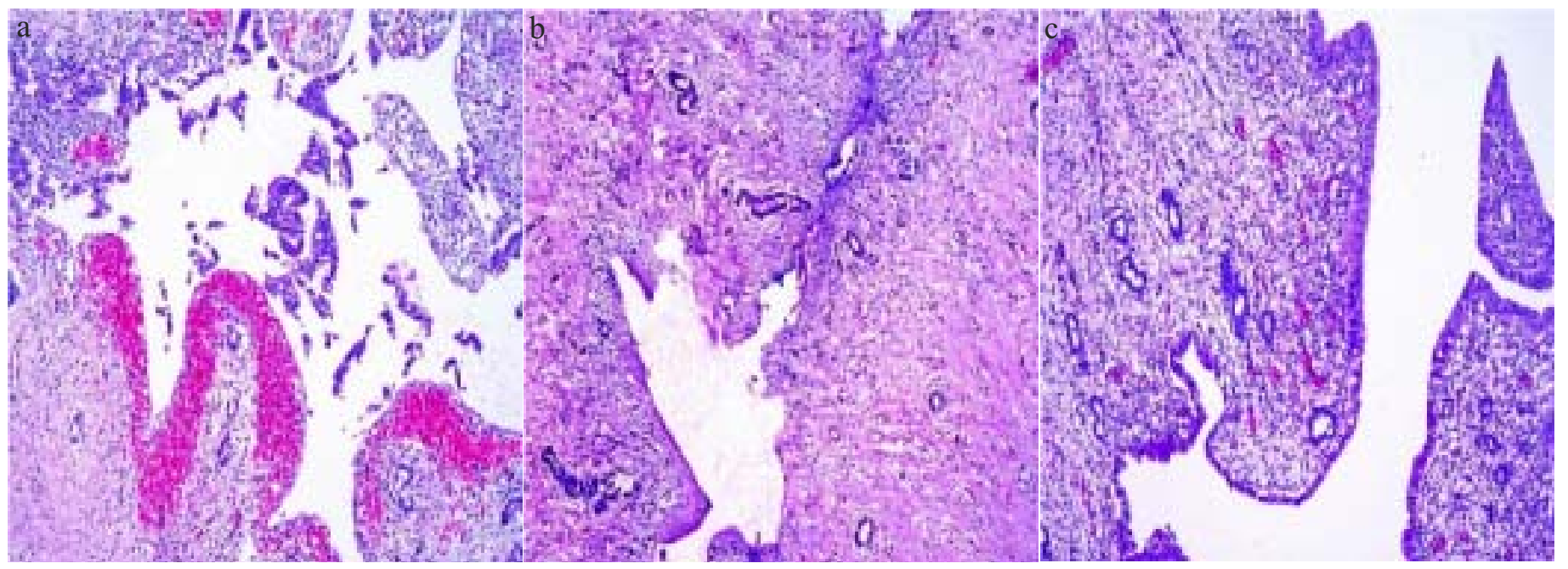

Figure 5: In the study group the comparison of the histomorphological results of the incised and un-incised horns amount of bleeding (a), detachment (b) and angiogenesis (c) significantly higher in the incised horns

$(p=0.049, p=0.049, p=0.048$, respectively) (H\&E, x100) 


\section{Discussion}

Keeping the wound healing to an optimum level at the incision site can be effective for the prevention of uterine scar detachments. An optimum level of wound healing in all tissues decreases development of fibrotic scar to a minimum and maintains the tissue stretching close to normal (10). While new fibrotic scar tissue creates a weak point in the uterus and disrupts tissue mechanics, inflammation and angiogenesis increase wound healing at the remodeling phase and provide an optimum level of wound stretching. With the evaluation of tissue tension force, numerical values were obtained regarding wound healing and the similarity to normal tissue after healing was assessed (11).

Uterine healing after surgery is a cascade beginning with the release of some growth factors, which continues, and excess release of these factors leads to formation of new pathological tissue, and in later periods, to uterine dehiscence with the increase of intrauterine pressure (12). Of these factors, VEGF is the factor playing a major role in angiogenesis, and provides influx of inflammatory cells to this region by increasing the blood flow $(13,14)$. TNF- $\alpha$ has been demonstrated to have a role in angiogenesis and inflammation in uterine myometrium tissue (13-15). PDGF takes part as chemotactic agent and provides fibroblast migration to this area and allows formation of the extracellular matrix (13). Thus, when improvement of wound healing in this region is desired, it is necessary to provide the release of these mediators. Attempts at development of treatment methods for this have been made and positive results have been obtained. Bowers et al. have used growth factors to increase wound healing at this site and have demonstrated that tissue thickness and the tissue stretching force has increased and the amount of cells has decreased (16).

Fibroblast Growth Factor (FGF) is one of the treatments used for scar-developed uterus and its positive effects on the regeneration phase of rat uterine horns has been demonstrated (17). The uterine scar treatment applied by Nancheng et al. with collagen-dependent VEGF has been demonstrated to increase endometrial and muscular regeneration and also vascularization of the uterus at the remodeling phase (18).

In a study performed on sheep, grafts obtained from pig intestinal submucosa have been used to increase myometrium healing at the incision line, and it has been demonstrated that tissue thickness and neo-angiogenesis increased and contrary to this, adenomyosis and inflammation did not increase (19). No difference was seen between the graft-applied and nongraft-applied groups in the tissue stretching test.

In various pre-clinic studies, MSCs of adipose tissue origin have been used in various tissues in order to provide wound healing, and positive results have been obtained $(20,21)$. Gimble et al. have demonstrated how MSCs of adi- pose tissue origin activate the paracrine pathways with the cytokines and growth factors they release in the adipose tissue (22). It has been emphasized that MSCs of adipose tissue origin increase the presence of antioxidants, free radical sweepers, chaperons and heat shock proteins at the ischemic area, which provides a positive effect on wound healing (22). MSCs of adipose tissue origin transplanted onto the wounded site locally was used at the colonic anastomosis line in a study conducted by Yoo et al., and it was observed that they increased angiogenesis and consequently, healing (23).

Jun et al. used stem cells of muscle origin in the incision model for uterine smooth muscle healing in the incision model developed for rats and observed that healing was increased, and predicted that uterine rupture rates would decrease with this treatment in the pregnancy process following myomectomy (24). The effects of autologous stem cells of bone marrow origin on the scar tissue of rat uterus were examined with the light microscope and observed that it increased angiogenesis (25).

There are many methods in obtaining MSCs of adipose tissue origin. There are different techniques in the literature that mostly include enzymatic methods for the isolation of MSCs from adipose tissue. For example, Zuk et al. obtained MSCs of adipose tissue origin with this method from human loose adipose tissue. In this method, fat tissue aspirates were washed with sterile phosphate-buffered saline (PBS) and contaminated debris and red blood cells were removed. The washed aspirates were slightly shaken with $0.075 \%$ collagenase (Type 1) in PBS for 30 minutes at $37^{\circ} \mathrm{C}$. Collagenase was inactivated, and the cellular pellet was centrifuged for 10 minutes and then placed into a culture medium and filtered from 100$\mu \mathrm{M}$ filter, and the last debris was removed and then, the cells were cultured (26). In another study, adipose tissue obtained from the abdominal subcutaneous tissue of New Zealand white rabbit was used. After the adipose tissue had been fractionated into small pieces, it was slightly mixed in a water bath for 2.5 hours at $37^{\circ} \mathrm{C}$ in order to be digested with albumin-absorbed collagenase and trypsin. After the cells had been centrifuged at $1500 \mathrm{x} g$ for 10 minutes, the cell pellet was washed and cultured (27). Cao et al. used $0.2 \%$ collagenase for enzymatic digestion in order to obtain MSC from human loose adipose tissue (28). Katz et al. used enzymatic solutions when isolating MSCs from human subcutaneous adipose tissue (29). This study is distinguished from others with filtering the tissue to remove the debris and centrifuging the residual cell suspension. The cell suspension was exposed to an osmotic buffer for lysis of the erythrocytes. In most of the recent studies, MSCs have been isolated using collagenase digestion, and the red blood cells were removed with the lysis buffer $(30,31)$.

On the contrary, in our study, neither one of the enzymatic digestions, nor filtering and osmotic buffering for removal of red blood cells, were used for the cell isolation and culture 
technique. MSCs are directly isolated using the explant culture method. For this reason, one of the most important advantages of this study is that it is easy, cheap and safer, and at the same time it does not use an enzymatic method.

Adipose tissue originated MSCs express specific cell surface proteins such as the bone marrow MSCs. For rapid identification of the cell populations, generally surface protein expression analysis is used $(22,26)$.

The characterization markers of the MSCs are CD13 and CD29 molecules $(32,33)$. These molecules are not only markers, but receptors at the same time that play a role in angiogenesis (34).

MSCs have to express some cytokine receptors, extracellular matrix components and necessary growth factors for adhesion, migration, proliferation and differentiation. Of these molecules determined with the flow cytometer in MSCs, while CD29, CD90, CD54 and MHC Class 1 are positive, CD45, CD106 and MHC Class 2 are negative (35-41). The minimum homogeneity of MSCs of adipose tissue origin prepared with the simple technique is $98.68 \%$ (8).

In order to eliminate the probability of uterine rupture in pregnancies after previous uterine surgery, the wound healing should be kept at optimum level and preventive approaches that will provide new tissue formation close to the normal tissue may be beneficial. Taking the histologic structure and embryonic origin of the uterus into consideration, similarities between surface markers of the MSCs with uterus have been determined in a limited number of studies conducted in this area. These cells have a differentiation ability in similar quality to normal tissue in the uterus and new tissue formation including less fibrotic tissue have been observed $(24,25)$. Of the MSCs that will be used for this purpose, MSCs of adipose tissue origin are applicable and easy to obtain, are prepared with a different method than the methods tried in many studies so far, and it is used in our study in the experimental uterine scar model in the rat uterus.

When the previous studies were considered, we see that the histopathological findings were more frequently evaluated for angiogenesis and the inflammatory cell response. In our study, in terms of wound healing, we revised the mentioned parameters as: detachment, bleeding, edema, mononuclear cell infiltration and angiogenesis suggested that addition of factors that delayed wound healing will provide a more significant evaluation. We determined a significant difference between the groups statistically, in particular, according to the presence of edema $(\mathrm{p}<0.05)$.

An increase in angiogenesis increases the inflammatory cell migration to the tissue together with the increased blood flow to the tissue. In our study, the positive effects of MSCs of adipose tissue origin on uterine scar are demonstrated, al- though the difference was not significant. Edema, which has the effect of delaying wound healing and which can be the sign of absence of optimal healing, was observed to be significantly higher in the control group uterine horns than the incised uterine horns in the experiment group $(\mathrm{p}<0.05)$. No significant difference was observed between the other factors that delayed wound healing.

In the literature search for uterine wound healing using MSC, no study existed evaluating the healing in terms of histological and functional aspects. In our study, the rat uterus was evaluated by means of the histological healing indicators after a healing period of 1 month and were exposed to tissue stretching test to observe the resistance of tissue. All of the uterine horns were weighed separately before the stretching test.

The weights of the non-incised uterine horns in the control group were statistically significantly higher than the weights of the incised uterine horns $(\mathrm{p}=0.012)$. These data show us that there was tissue loss in the incised uterine horns despite the completed tissue healing. On the contrary, in the experiment group, the weights of the intact uterine horn were found to be statistically significantly lower than the weights of the incised uterine horn $(p=0.012)$. In the experiment group, the tissue renewed itself at the incised horn due to the MSCs of adipose tissue origin application. When compared to the intact but non-MSC-applied atrophied horn, the weight was measured to be higher in the incised experimental group horn.

In many previously performed studies related with wound healing in rats, the tissue stretching test has been used to measure the resistance of scar tissue. In this regards, a numerical value showing how close it approached normal tissue strength with the applied treatment responses was produced $(11,16$, 19). In our study, the tissue stretching test was utilized and the difference between the incised and the non-incised uterine horn stretching values in both groups was measured. In the control group, the resistance of non-incised horns to stretching was significantly higher than that of the incised horns statistically, and this demonstrates that the probability of rupture in uterus tissue exposed to trauma is higher than that of the natural state of the same tissue. In the experiment group, no significant difference was observed between the resistances to stretching of the incised and the non-incised uterine horns. It is the quality of wound healing in scar tissue that increased the probability of rupture. Application of MSCs of adipose tissue origin can have a positive effect at the wound healing.

The weight values of the incised and the non-incised uterine horns were compared between the experiment and control groups and there was no significant difference for the non-incised uterine horn weight values. Similarly, there was no significant difference between the incised uterine horn weight values. Another finding of the analysis was that there was no difference between the non-incised uterine horn stretching values of the experiment and the control groups; however, the 
difference between the incised uterine horn stretching values was significant $(\mathrm{p}<0.05)$. These values can give us an idea about the estimated size of the uterine horns, and the resistance to mechanical effects that were similar before the uterine scar model developed in the rats used in our study. The experiment group withstands the stretching of the incised uterine horns to a higher extent than the control group and this may conclude that the MSCs of adipose tissue origin can affect wound healing positively and can decrease the probability of uterine rupture.

Uterine scars and the risk of uterine rupture due to these are major complications with maternal and fetal morbidity and mortality in women at reproductive age. Considering the risk, most of the clinicians and the patients prefer caesarian as the delivery method. With repetitive caesarian sections, the patients undergo operations and encounter the risks. The effectiveness of preventive approaches such as MSCs of adipose tissue origin that would provide optimal wound healing in the scar tissue may lead to a significant decrease in the necessity of repeat uterine surgeries.

\section{References}

1. Evans MJ, Kaufman MH. Establishment in culture of pluripotential cells from mouse embryos. Nature $1981 \mathrm{Jul}$ 9;292(5819):154-6.

2. Khosrotehrani K Mesenchymal stem cell therapy in skin: why and what for? Exp Dermatol 2013 May;22(5):30710 .

3. Reyes M, Verfaillie CM. Turning marrow into brain: Generation of Glial and neuronal cells from adult bone marrow mesenchymal stem cells. In Blood 1999 Nov 15; 94(10):377A-377A

4. Horwitz EM, Le Blanc K, Dominici M, Mueller I, SlaperCortenbach I, Marini FC, et al. Clarification of the nomenclature for MSC: The International Society for Cellular Therapy position statement. Cytotherapy 2005 Jan 1; 7(5):393-5.

5. Gimble JM, Bunnell BA, Frazier T, Rowan B, Shah F, Thomas-Porch $\mathrm{C}, \mathrm{Wu} \mathrm{X}$. Adipose-derived stromal/stem cells: a primer. Organogenesis 2013;9(1):3-10.

6. Ivanova-Todorova E, Bochev I, Dimitrov R, Belemezova K, Mourdjeva M, Kyurkchiev S, Kinov P, Altankova I, Kyurkchiev D. Conditioned medium from adipose tissuederived mesenchymal stem cells induces CD4+FOXP3+ cells and increas IL-10 secretion. J Biomed Biotechnol 2012;2012:295167

7. Arrigoni E, de Girolamo L, Di Giancamillo A, Stanco D, Dellavia C, Carnelli D, et al. Adipose-derived stem cells and rabbit bone regeneration: histomorphometric, immunohistochemical and mechanical characterization. J Orthop Sci 2013 Mar;18(2):331-9.

8. Niyaz M, Gurpinar OA, Gunaydin S, Onur MA. Isolation, culturing and characterization of rat adipose tissue-de- rived mesenchymal stem cells: a simple technique. T J Biol 2012;36(6):658-64.

9. Lindroos B, Suuronen R, Miettinen S. The potential of adipose stem cells in regenerative medicine. Stem Cell Rev 2011 Jun;7(2):269-91.

10. Darby IA, Hewitson TD. Fibroblast differentiation in wound healing and fibrosis. Int Rev Cytol 2007;257:14379.

11. Buhimschi CS, Zhao G, Sora N, Madri JA, Buhimschi IA. Myometrial wound healing post-Cesarean delivery in the MRL/MpJ mouse model of uterine scarring. Am J Pathol $2010 \mathrm{Jul} ; 177(1): 197-207$.

12. Nakonieczny Z. Conduction of labor following cesarean section. Ginekol Pol 1962 Mar-Apr;33:251-8.

13. Werner S, Grose R. Regulation of wound healing by growth factors and cytokines. Physiol Rev 2003 Jul; 83(3):835-70.

14. Singer AJ, Clark RA. Cutaneous wound healing. N Engl J Med 1999 Sep 2;341(10):738-46.

15. Steenfos HH. Growth factors and wound healing. Scand J Plast Reconstr Surg Hand Surg 1994 Jun;28(2):95-105.

16. Bowers D, McKenzie D, Dutta D, Wheeless CR, Cohen WR. Growth hormone treatment after cesarean delivery in rats increases the strength of the uterine scar. Am J Obstet Gynecol 2001 Sep;185(3):614-7.

17. Li X, Sun H, Lin N, Hou X, Wang J, Zhou B, et al. Regeneration of uterine horns in rats by collagen scaffolds loaded with collagen-binding human basic fibroblast growth factor. Biomaterials 2011 Nov;32(32):8172-81.

18. Lin N, Li X, Song T, Wang J, Meng K, Yang J, Hou X, Dai $\mathrm{J}, \mathrm{Hu} \mathrm{Y}$. The effect of collagen-binding vascular endothelial growth factor on the remodeling of scarred rat uterus following full-thickness injury. Biomaterials 2012 Feb; 33(6):1801-7

19. O’Brien JM, Whetham D, Fecteau C, Jansen J, Hiles M. Augmenting myometrial healing after cesarean delivery: use of an adjuvant biologic graft placement in an ovine model. Am J Perinatol 2011 Aug;28(7):543-50.

20. Nambu M, Ishihara M, Nakamura S, Mizuno $H$, Yanagibayashi S, Kanatani Y, et al. Enhanced healing of mitomycin $\mathrm{C}$-treated wounds in rats using inbred adipose tissue-derived stromal cells within an atelocollagen matrix. Wound Repair Regen 2007 Jul-Aug;15(4):505-10.

21. Nambu M, Kishimoto S, Nakamura S, Mizuno $H$, Yanagibayashi S, Yamamoto N, et al. Accelerated wound healing in healing-impaired $\mathrm{db} / \mathrm{db}$ mice by autologous adipose tissue-derived stromal cells combined with atelocollagen matrix. Ann Plast Surg 2009 Mar;62(3):317-21.

22. Gimble JM, Katz AJ, Bunnell BA. Adipose-derived stem cells for regenerative medicine. Circ Res 2007 May 11;100(9):1249-60.

23. Yoo JH, Shin JH, An MS, Ha TK, Kim KH, Bae KB, et al. 
Adipose-tissue-derived Stem Cells Enhance the Healing of Ischemic Colonic Anastomoses: An Experimental Study in Rats. J Korean Soc Coloproctol 2012 Jun; 28(3):132-9.

24. Jun CR, Lee JY, Cho HH. Muscle-derived stem cells and smooth muscle healing in a rat model of uterine injury. Int J Gynaecol Obstet 2012 Mar;116(3):265-6.

25. Maiborodin IV, Yakimova NV, Matveyeva VA, Pekarev OG, Maiborodina EI, Pekareva EO. Angiogenesis in rat uterine cicatrix after injection of autologous bone marrow mesenchymal stem cells. Bull Exp Biol Med 2011 Apr; 150(6):756-61.

26. Zuk PA, Zhu M, Ashjian P, De Ugarte DA, Huang JI, Mizuno H, et al. Human adipose tissue is a source of multipotent stem cells. Mol Biol Cell 2002 Dec;13(12):427995.

27. Rangappa S, Fen C, Lee EH, Bongso A, Sim EK. Transformation of adult mesenchymal stem cells isolated from the fatty tissue into cardiomyocytes. Ann Thorac Surg 2003 Mar;75(3):775-9.

28. Cao Y, Sun Z, Liao L, Meng Y, Han Q, Zhao RC. Human adipose tissue-derived stem cells differentiate into endothelial cells in vitro and improve postnatal neovascularization in vivo. Biochem Biophys Res Commun 2005 Jul $1 ; 332(2): 370-9$.

29. Katz AJ, Tholpady A, Tholpady SS, Shang H, Ogle RC. Cell surface and transcriptional characterization of human adipose-derived adherent stromal (hADAS) cells. Stem Cells 2005 Mar;23(3):412-23.

30. Francis MP, Sachs PC, Elmore LW, Holt SE. Isolating adipose-derived mesenchymal stem cells from lipoaspirate blood and saline fraction. Organogenesis 2010 Jan-Mar; 6(1):11-4.

31. Baglioni S, Francalanci M, Squecco R, Lombardi A, Cantini G, Angeli R, et al. Characterization of human adult stem-cell populations isolated from visceral and subcutaneous adipose tissue. FASEB J 2009 Oct;23(10): 3494-3505.

32. Kode JA, Mukherjee S, Joglekar MV, Hardikar AA. Mesenchymal stem cells: immunobiology and role in immunomodulation and tissue regeneration. Cytotherapy 2009;11(4):377-91.
33. Ko MS, Jung JY, Shin IS, Choi EW, Kim JH, Kang SK, Ra JC. Effects of expanded human adipose tissue-derived mesenchymal stem cells on the viability of cryopreserved fat grafts in the nude mouse. Int J Med Sci 2011 Mar $14 ; 8(3): 231-8$.

34. Strem BM, Hicok KC, Zhu M, Wulur I, Alfonso Z, Schreiber RE, et al. Multipotential differentiation of adipose tissue-derived stem cells. Keio J Med 2005 Sep; 54(3):132-41.

35. Ode A, Kopf J, Kurtz A, Schmidt-Bleek K, Schrade P, Kolar P, et al. CD73 and CD29 concurrently mediate the mechanically induced decrease of migratory capacity of mesenchymal stromal cells. Eur Cell Mater 2011 Jul 6;22: 26-42.

36. Wiesmann A, Bühring HJ, Mentrup C, Wiesmann HP. Decreased CD90 expression in human mesenchymal stem cells by applying mechanical stimulation. Head Face Med 2006 Mar 31;2:8.

37. González MA, Gonzalez-Rey E, Rico L, Büscher D, Delgado M. Adipose-derived mesenchymal stem cells alleviate experimental colitis by inhibiting inflammatory and autoimmune responses. Gastroenterology 2009 Mar;136(3):978-89.

38. Spath C, Schlegel F, Leontyev S, Mohr FW, Dhein S. Inverse Relationship between Tumor Proliferation Markers and Connexin Expression in a Malignant Cardiac Tumor Originating from Mesenchymal Stem Cell Engineered Tissue in a Rat in vivo Model. Front Pharmacol 2013 Apr 17;4:42.

39. Ode A, Kopf J, Kurtz A, Schmidt-Bleek K, Schrade P, Kolar P, et al. CD73 and CD29 concurrently mediate the mechanically induced decrease of migratory capacity of mesenchymal stromal cells. Eur Cell Mater 2011 Jul 6;22: 26-42.

40. Wiesmann A, Bühring HJ, Mentrup C, Wiesmann HP. Decreased CD90 expression in human mesenchymal stem cells by applying mechanical stimulation. Head Face Med 2006 Mar 31;2:8.

41. Yang XF, He X, He J, Zhang LH, Su XJ, Dong ZY, Xu YJ, Li Y, Li YL. High efficient isolation and systematic identification of human adipose-derived mesenchymal stem cells. J Biomed Sci 2011 Aug 19;18:59 